\title{
An Empirical Study on the Mechanism of Institutional Innovation Driving Foreign Trade Competitiveness
}

\author{
You Yu Cong ${ }^{1, a^{*}}$, Yi Lu Xia ${ }^{2, b}$, \\ ${ }^{1}$ Guangzhou College of Business and Technology, Guangzhou, Guangdong, China \\ ${ }^{2}$ Guangzhou College of Business and Technology, Guangzhou, Guangdong, China \\ astoneyyc@163.com, b61070262@qq.com, \\ * You Yu Cong
}

Keywords: Institutional Innovation Drive, Foreign Trade, Empirical Study, Competitiveness

\begin{abstract}
This paper has, by means of questionnaires, conducted a large-sample survey of representative typical foreign trade enterprises in Guangdong Province, followed by an exploratory case study. Reliability and validity analysis, together with the SEM, were applied to verify and form a better fit model, so as to conduct an empirical analysis of the mechanism of how institutional innovation drives the competitiveness of foreign trade enterprises. The results show that institutional innovation, through the three sub-levels (government, businesses and market), exerts a positive impact upon the competitiveness of foreign trade enterprises.
\end{abstract}

\section{Introduction}

The competitiveness of foreign trade has always been the focus of academic and business attention. Both neo-classical trade theory and new trade theory have conducted a pioneering exploration and interpretation on this field from the factors of endowment differences, cost and technical differences, economies of scale and other direct factors concerning foreign trade competitiveness. But what led to the differences in these direct factors? Modern trade theory rarely studied the mechanism of institutional factors in the process of international competition. The new institutional school did not study the relationship between institutional reform and foreign trade competitiveness, and it was not easy to quantify the institutional factors, which led to the lack of rigorous empirical support for the relationship between the two. This leads to the existence of "gap" between the theory of modern foreign trade superiority and the new system theory. Therefore, this study takes this "gap" as the starting point, aiming to explore the relationship between the two and fill this "gap". The present study analyzed the role of institutional factors in the process of international competition, hopefully to contribute to the field of theory and application of literature.

\section{Literature Review}

Simon (2010) pointed out that: institutional innovation factors, by greatly reducing the cost of trade, improve the efficiency of foreign trade resources and promote import and export performance. Joseph's (2011) study shows that institutional innovation and a sound foreign trade infrastructure affect a given region's import and export flows, trade levels, patterns and sizes, and ultimately jointly determines the region's export performance. Vertinsky (2013) points out that institutional innovation in a given region is inversely proportional to opportunistic behavior in foreign trade, and that the better the system innovation is, the transaction costs of the exit will be greatly reduced. Newbert (2015) pointed out that the impact of institutional innovation on the export performance of foreign trade enterprises in a new economy is positively related to the size and age of foreign trade enterprises. Zhang Yabin (2000) explores the mechanism of institutional innovation on foreign trade from the perspectives of technological innovation, transaction cost and economies of scale, and concludes that a country's institutional innovation is the most important factor affecting its foreign trade scale and performance. You Yu-cong et al. (2016) studied the important role of institutional innovation in 
technological innovation from both macro and micro levels and concluded that institutional innovation promoted the improvement of foreign trade model. In recent years, many domestic and foreign scholars ,through the comparative study of competitiveness and comparative advantage, claimed that the role of institutional innovation is positive in the formation of a regional competitive advantage (Antràs, 2013; Helpman, 2014; Zhang Haiwei 2011,2012; Liu Zhibiao, 2010; Zhang Jie, 2011; Hu Guheng, 2013; Lin Jianhong, 2014; You Yu-cong,2016).

\section{Research Design}

3.1 Research Question \& Hypothesis. In the present study, Guangdong foreign trade enterprises function as a research unit and we combined three economic systems in terms of the micro (enterprise), market (transactions), government (macro) to research the competitiveness of Guangdong 's foreign trade enterprises by using the sub - index and the innovative elements of the empirical system. This paper puts forward the hypothesis that institutional innovation elements cast a positive impact upon the competitiveness of foreign trade enterprises.

3.2 Methods. This present study is based on the method of "case study", on the grounds that case study is an effective and strong empirical approach. Yin (2012) describes the applicable conditions of the case study method: when the object to be studied or the boundary between the phenomenon and the objective situation in which it is located is not obvious. Case study is widely used to study objects or phenomena that are currently being carried out without departing from the actual objective environment. Because the data of the innovation system involved in the case study can not be checked from the existing public information, the research method decided to use the questionnaire for the foreign trade enterprise to collect the relevant data, and then through the data, analysis and other specific steps are conducted for the empirical research. This paper explored the driving mechanism of the competitiveness of foreign trade enterprises in Guangdong Province, and selected 50 most representative foreign trade enterprises in Guangdong from a large number of investigation cases.

3.2.1 Questionnaire Design Principles and Procedures. In order to ensure the reliability and validity of the survey data, the Questionnaire designed to strictly adhere to the principle of qualitative and quantitative. The content of Questionnaire is subject to the relevant research variables to measure, and in strict accordance with the Likert (2000) scale method, through a number of objections or views of the object of the composition of the subject. The criteria for the Questionnaire are based on the $\mathrm{Li}$ Kaizu (2004) method. The design procedure strictly follows the Questionnaire design by Dunn (1994), which is a four-step process (pictured).

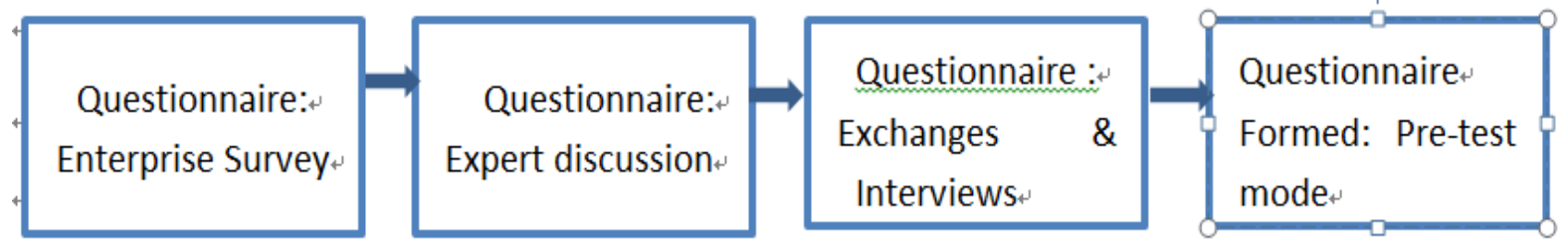

3.2.2 Questionnaire Object. In order to ensure the validity of the research results and the reliability of the sample data, this study strictly controls the object, the delivery area and the channel when the questionnaire is issued. As the main concern of this research is the innovation of the foreign trade enterprises in Guangdong Province, it is only issued in the top management of the foreign trade enterprises (service life> 3 years) to ensure high quality and reliability.

3.3 Variables. The variables involved in this study include microeconomic (enterprise), market (trade), government (macro). Because it is difficult to quantify the measure of these variables, this study, according to Likert (2000), has applied the five-level scale to the relevant measure. The scale design is based on literature, field and expert advice(Howells,2003; Yang Zhenning et al. 2007;Long Jing et al. 2012). 


\section{SEM Model}

In order to study the intrinsic relationship between the variables, this study constructed the Structural Equation Modeling (SEM) to infer the hidden variables by measuring the variables of the model and test the hypothesis. In the conceptual model of this study, the variables involved in the subdivision are three economic systems (micro) (business), market (trade) and government (macro); the SEM model can effectively aid the conceptual model.

4.1 Confirmatory Factor Analysis. Through the exploratory factor analysis, this part of the research variables to do confirmatory factor analysis, the purpose is to test the measured variables of the factor structure and the original idea of consistency. In this study, 201 questionnaires were collected and divided into two parts, 101 cases were used to confirm the factor analysis (50 for the previous exploratory factor analysis).

\begin{tabular}{|c|c|c|c|c|}
\hline Drive path & Standard Path & Path Coefficient & C.R. & $p$ \\
\hline Competiveness+ Policy Support & .631 & 1.00 & 3.584 & $* * *$ \\
\hline Competiveness & .627 & 1.21 & 3.881 & $* * *$ \\
\hline Competiveness $\quad$ Property Support & .701 & 1.47 & 4.141 & $* * *$ \\
\hline$\chi^{2}$ & 90.441 & $\mathrm{CFI}$ & & .898 \\
\hline$d f$ & 31 & TLI & & .888 \\
\hline$\chi^{2} / d f$ & 2.912 & RMSEA & & .106 \\
\hline
\end{tabular}

The results of the institutional innovation measurement model show that $=90.441$, DO $=31$; $/=$ 2.912; CFI and TLI are close to 0.9 and RMSEA $=0.106$. The path coefficient is statistically significant at $\mathrm{p}<0.001$ level, showing that the fitting effect of the model is better. The division and measure of variables are valid.

4.2 Structural Equation Model Fitting Results. The reliability and validity analysis (exploratory + verifiability) show that the measurement model has a good fitting effect, and the structural equation model can be used to study the mechanism of the innovation function of the system innovation ability to the foreign trade enterprise and verify the research hypothesis.

\section{Conclusion}

Based on the structural equation model, the institutional innovation model of the competitiveness of foreign trade enterprises was modeled. Empirical results show that the research hypothesis has been confirmed, the system innovation elements have a positive impact on the competitiveness of foreign trade enterprises. Through the reliability and validity analysis and SEM verification analysis, the formation of a better fit model has come into reality. The rest of the study hypothesis is validated except that the path of "competitive intensity - competitiveness" is not verified. Government system innovation can promote the competitiveness of foreign trade enterprises through policy support, fund support and property right protection system, and positively affect the competitiveness of foreign trade enterprises. The innovation of market system can promote the competitiveness of foreign trade enterprises through competitive innovation products and competitive innovation cooperation factors, Positive impact on the competitiveness of foreign trade enterprises; competitive degree of the path is 
not significant. The innovation of internal system can promote the competitiveness of foreign trade enterprises through the support of innovation activities, the challenge challenge innovation and the performance reward correlation factor, and positively affect the competitiveness of foreign trade enterprises.

In short, through the above analysis, institutional innovation, through three sub-level of government, businesses and market system, throws a positive impact on the competitiveness of foreign trade enterprises.

\section{Acknowledgement}

This research was financially supported by the Guangdong Provincial Philosophy and Social Sciences "thirteen five" planning 2016 annual academic projects (Guangdong foreign trade "supply side reform" driven development path analysis, Grant No. GD16XYJ30), Guangzhou College of Business and Technology 2016 issue (Grant No.KA201602), online MOO demonstration course, Grant No. ZL20161226 and the 2016 project of Northeast Normal University (Grant No. 2016NNUP04)..

\section{References}

[1] Howells .J intermediation and the role of intermediaries in innovation[J]. Research Policy,2006

[2] Michael Porter. National Competitive Advantage [M]. Beijing: Huaxia Publishing House, 2002

[3] Grossman, G.M. and Helpman, E.rade; Innovation and Growth[M]. Princeton, Woodrow Wilson School-Public and International Affairs.1989;

[4] You Yucong. Comparative Advantage, Transaction Cost and Empirical Study on the Driving Path of Guangdong's Foreign Trade System Innovation [J]. Social Sciences, 2016

[5] You Yu-cong, Yi Luxia. An Innovation Research on Education Statistical Work in In Big Data Era [C] .2016ICEMS Proceedings （ISTP Compendex）;

[6] Zhang Yinyin, Deng Ling. Innovation to drive the transformation and upgrading of traditional industries to strategic emerging industries: mechanism and path $[\mathrm{J}]$. Economic system reform, 2016;

[7] Hong Yinxing. Several important concepts about innovation-driven and innovative economy [J]. Mass, 2011;

[8] ZHANG Li-wu.On the Innovation Driven Development [J]. Chinese Soft Science, 2015; 